\title{
COMUNICAÇÃOCIENTÍFICA
}

\section{MORTE SÚBITA DOS CITROS: SUSCETIBILIDADE DE SELEÇÕES DE LIMÃO-CRAVO E USO DE INTERENXERTOS ${ }^{1}$}

\author{
JORGINO POMPEU JUNIOR ${ }^{2} \&$ SILVIABLUMER 3
}

RESUMO - A morte súbita dos citros é uma doença que afeta cultivares de laranjas e tangerinas enxertadas nos limões-Cravo e Volkameriano. Ela foi observada em plantas com dois a seis anos de idade que, após mostrarem sintomas gerais de declínio, entraram em colapso e morreram. A retirada da casca dos porta-enxertos suscetíveis revela o amarelecimento na região cambial, sendo esse o sintoma-diagnóstico da doença e que precede os sintomas da copa. As plantas enxertadas nas tangerinas Cleópatra e Sunki, no trifoliata e no citrumelo Swingle, não mostram sintomas da doença. A transmissão por borbulha e a evolução espacial sugerem que a morte súbita dos citros seja causada por patógeno transmitido por vetor alado. Com o objetivo de selecionar porta-enxertos tolerantes à doença, laranjeiras Valência enxertadas em 254 porta-enxertos foram plantadas em maio de 2003 e 2004 em solos onde foram erradicados pomares afetados pela morte súbita dos citros e próximos a pomares afetados pela doença. Em novembro de 2006, o sintoma-diagnóstico da doença estava presente em dez seleções de limão-Cravo: Santa Barbara red lime, Borneo red lime, LimãoCravo Taquaritinga, Rangpur India C-26-1, Rangpur rose lemon, Rangpur Kusaie lime, Rangpur red lime D-33-40, Rangpur Egyptian lime, Rangpur lemon India e Japanshe citroen. A presença de interenxerto de trifoliata ou de tangerina Cleópatra, entre o limão-Cravo e a laranja Valência, não impediu a manifestação da doença.

Termos para indexação: doença, declínio, Citrus limonia, citrumelo Swingle

\section{CITRUS SUDDEN DEATH: SUSCEPTIBILITY OF RANGPUR LIME SELECTIONS AND THE USE OF INTERSTOCKS}

\begin{abstract}
Citrus sudden death (CSD) or morte súbita dos citros affects sweet orange cultivars and some mandarin trees grafted on Rangpur lime and Volkamer lemon rootstocks. The disease was observed in trees with ages ranging from two to six years; after showing general decline symptoms, the affected trees suddenly collapse and die. Trees on Cleopatra and Sunki mandarins, 'Swingle' citrumelo and trifoliate orange showed no symptoms of CSD. Cambial yellowing in the rootstock can be observed being this the main diagnostic symptom of the disease. The transmission of CSD by graft-inoculation and the spatial evolution suggest that CSD is caused by an insect-vectored pathogen. In order to search for tolerant rootstocks five nursery trees of Valencia sweet orange budded on each of 254 rootstocks were planted in May 2003 and May 2004 in soils were citrus trees affected by CSD were eradicated. Until November 2006, symptoms of the disease were observed on trees budded on the following Rangpur lime selections: Santa Barbara red lime, Borneo red lime, Limão Cravo Taquaritinga, Rangpur India C-26-1, Rangpur rose lemon, Rangpur Kusaie lime, Rangpur red lime D-33-40, Rangpur Egyptian lime, Rangpur lemon India and Japanshe citroen. The use of an interstock of trifoliate or Cleopatra mandarin between Rangpur lime and the Valencia sweet orange scion did not avoid the disease.
\end{abstract}

Index terms: disease, citrus decline, Citrus limonia, Swingle citrumelo.

Desde 1999, uma nova doença, inicialmente observada no município de Comendador Gomes (MG), e denominada de morte súbita dos citros (MSC) ou citrus sudden death (CSD) (Muller et al., 2002), vem afetando laranjeiras (Citrus sinensis L. Osbeck): cvs Valência, Pêra, Hamlin, Natal, Westin, Rubi e Pineapple, e tangerineiras (C. reticulata Blanco) cvs Cravo e Poncã enxertadas em limão-Cravo (C. limonia L. Osbeck) no sudoeste de Minas Gerais e no Norte de São Paulo (GimenesFernandes \& Bassanezi, 2001; Bassanezzi et al., 2003). Posteriormente, o problema foi encontrado em laranjeiras enxertadas no limão Volkameriano (C. volkameriana V. Tennore et Pasquale), as quais exibem sintomas menos severos que os observados nas laranjeiras sobre limão-Cravo. Inicialmente, as folhas das plantas afetadas perdem o brilho, adquirem coloração verde-pálida, seguida da queda das folhas e morte dos ramos apicais, culminando com o perecimento das plantas, cerca de seis meses após o aparecimento dos sintomas. A retirada da casca dos porta-enxertos suscetíveis revela um amarelecimento na região cambial, sendo esse o sintoma-diagnóstico da doença e que precede os sintomas da copa (Gimenes-Fernandes \& Bassanezzi, 2001). A MSC já foi observada em plantas com dois anos de idade, sendo mais freqüente naquelas com mais de seis anos. Plantas enxertadas sobre tangerinas Cleópatra (C. reshni hort. ex Tanaka) e Sunki [C. sunki (Hayata) hort. ex Tanaka],

${ }^{1}$ (Trabalho 212-07). Recebido em: 04-09-2007. Aceito para publicação em: 28-03-2008. Projeto desenvolvido com recursos do Processo MCT/CNPq 50.0043/02-7: Morte Súbita dos Citros: etiologia, epidemiologia e controle.

${ }^{2}$ Pesquisador do Centro APTA Citros Sylvio Moreira, 13490-970, Cordeirópolis-SP. Bolsista de Produtividade do CNPq. Email: jorgino@centrodecitricultura.br.

${ }^{3}$ Pós-Doutoranda do Laboratório de Fisiologia e Bioquímica Fitopatológica, Esalq-USP, 13418-900, Piracicaba-SP. Bolsista da CAPES/PRODOC. Email:blumer@esalq.usp.br 
citrumelo 'Swingle' [C. paradisi Macfaden x Poncirus trifoliata (L.) Rafinesque] e trifoliata (Poncirus trifoliata Rafinesque) são assintomáticas.

A distribuição espacial e temporal das plantas afetadas pela MSC mostrou similaridade com a distribuição das plantas afetadas pelo vírus causador da tristeza dos citros, nas condições onde o afidio Toxoptera citricidus Kirk. é o vetor do vírus (Bassanezzi et al., 2003). Essa similaridade sugere que a MSC possa ser causada por um patógeno, como uma nova estirpe do vírus da tristeza dos citros ou um novo vírus pertencente à família Tymoviridae (gênero Marafivirus) e transmitido por inseto (Bové et al., 2002; Maccheroni et al., 2005). A doença foi transmitida por inoculação de plantas sadias, utilizando borbulhas retiradas de plantas sintomáticas, enxertadas em limão-Cravo e de plantas assintomáticas, enxertadas em tangerina Cleópatra (Yamamoto et al., 2003), o que demonstra que a MSC é infecciosa e causada por agente biótico. Indica também que o agente causal pode estar presente nas plantas enxertadas e nas subenxertadas com porta-enxertos tolerantes.

A convivência com a MSC vem sendo feita pela utilização dos porta-enxertos tolerantes, quer pela subenxertia das plantas no campo, quer pelo plantio de mudas formadas sobre esses porta-enxertos.

Com o objetivo de determinar a tolerância à doença de potenciais porta-enxertos selecionados no Banco Ativo de Germoplasma de Citros do Centro APTA Citros Sylvio Moreira, do Instituto Agronômico de Campinas, em Cordeirópolis (SP), mudas de laranja Valência enxertadas em 181 porta-enxertos foram plantadas em maio de 2003, em duas áreas que tiveram pomares erradicados pela presença da MSC, sendo uma em Barretos (SP) e outra em Comendador Gomes (MG), ambos em Latossolo Vermelho-Amarelo, sob clima Cwa, no espaçamento de 7,5m x $3,5 \mathrm{~m}$ e cultivadas sem irrigação. Os experimentos são vizinhos de pomares portadores da MSC, que serviram de fontes do inóculo.

Em maio de 2004, foram acrescentadas ao experimento situado em Comendador Gomes mudas formadas sobre 73 portaenxertos cedidos pela Universidade da Califórnia, Estação Experimental Agroindustrial, de Tucuman, Argentina, e pelo Eng. Agr. Dr. José Eduardo Oliveira de Lima, em Casa Branca-SP.

A escolha da laranja 'Valência' teve como razões a sua suscetibilidade à MSC quando enxertada nos limões-Cravo e Volkameriano, e ser a segunda cultivar-copa mais importante da citricultura paulista. A utilização da laranja-Pêra, a mais importante copa da citricultura brasileira, possibilitaria a ocorrência de incompatibilidade (formação de anel de goma na linha de enxertia) entre essa copa e diversos porta-enxertos, como os limões rugosos, trifoliatas e seus híbridos, o que afetaria os resultados pretendidos.

Foram plantadas parcelas de cinco mudas de cada combinação, sem repetição, agrupadas pela espécie ou pelos parentais (ex. limões-cravos, citrumelos), visando a facilitar as observações e comparações entre os porta-enxertos que mostrassem tolerância a MSC. Foram também plantadas seis parcelas de cinco mudas de laranja 'Valência' enxertadas em limãoCravo, distribuídas aleatoriamente pelo pomar experimental e destinadas a servirem de indicadoras da presença da doença no experimento.

Nos experimentos, foram avaliados 33 seleções e híbridos de limão-Cravo, a seguir relacionados com seus números de registro no Banco Ativo de Germoplasma de Citros do Centro APTA, Citros Sylvio Moreira: Rangpur Otaheite orange 12901(859), Rangpur 'India' 26.1(860), Rangpur 'Red Ling Ming'(861), Rangpur Red Lime D.33.40(863), Limão-Cravo Limeira(862) Rangpur Rose Lemon(864), Rangpur 'Kusaie' Lime(865), Rangpur Red Lime D.33.30(866), Rangpur Red Lime D.33.47(867), Rangpur Rose Lime(868), Limão-Cravo 'Taquaritinga' (869), Limão-Cravo EEL(871), Rangpur 'Egyptian Lime' (872), Rangpur Lemon India(873), Rangpur 'Borneo' red(874), Rangpur Australian Red(875), Citrus pennivesiculata(880), Japanshe citroen(882), Phylipine Red Lime(883), 'Santa Barbara' Red Lime(884), Limão-Cravo da Califórnia(1467), Limão-Cravo Ipanema(1522), Bishop Rangpur Lime, Rangpur Santa Bárbara, Limão-Cravo Citrolima, LimãoCravo x Laranja Azeda(1468), Limão Cravo x Citrange Carrizo(1524), Limão-Cravo x Citrange ‘Troyer', Rangpur Lime x Trifoliata 60110(1642), Rangpur Lime x Trifoliata 5320(1644), Rangpur Lime x Trifoliata 3810(1648), Limão-Cravo x Trifoliata Swingle B(1695) e Limão-Cravo x Trifoliata Swingle A (1707).

Em novembro de 2006, no experimento conduzido em Barretos, constatou-se que o sintoma-diagnóstico da MSC (amarelecimento da região cambial do porta-enxerto) estava presente em dez seleções de limão-Cravo: 'Santa Barbara' red lime, 'Borneo' red lime, Limão- Cravo 'Taquaritinga', 'Rangpur' India C-26-1, Rangpur rose lemon, Rangpur 'Kusaie' lime, Rangpur red lime D-33-40, Rangpur 'Egyptian' lime, Rangpur lemon 'India' e Japanshe citroen. Nenhuma das plantas mostrava sintomas foliares, porém algumas exibiam "pencas" de frutos, atípicas para a cultivar Valência, e que em sua maioria estavam relacionadas à presença dos sintomas no porta-enxerto.

O sintoma-diagnóstico da MSC não foi observado em nenhuma planta do experimento conduzido em Comendador Gomes até dezembro de 2006.

A ocorrência do sintoma-diagnóstico somente no experimento conduzido em Barretos deve ser consequiência dos tratos culturais diferentes e da presença de maior número de plantas afetadas e maior intensidade da doença nos pomares circundantes deste experimento que no experimento situado em Comendador Gomes.

Desde a década de 1960, o limão-Cravo é o principal portaenxerto da citricultura paulista, razão pela qual a utilização de métodos que possibilitem a continuidade do uso desse portaenxerto, deve ser avaliada.

Tendo em vista a não-manifestação da MSC em laranjeiras enxertadas na tangerina Cleópatra e no trifoliata, esses dois porta-enxertos foram utilizados como interenxerto entre a laranja Valência e o limão-Cravo visando a impedir a passagem do patógeno e assim possibilitar a continuidade do uso deste porta-enxerto. Outra razão da escolha do trifoliata levou em conta ser ele imune aos complexos viróticos da tristeza que predominam em São Paulo, e que uma das possíveis causas da MSC seria uma nova estirpe do vírus da tristeza dos citros. Julgou-se necessário 
proceder a este trabalho, embora tentativa semelhante houvesse sido infrutífera quando do advento da tristeza em São Paulo, no final dos anos 30, quando porta-enxertos tolerantes a essa virose foram utilizados como interenxertos entre copas de laranjas e a laranja-Azeda.

Em dezembro de 2004, cinco mudas de laranjeira Valência enxertadas em limão-Cravo e interenxertadas com tangerina Cleópatra ou trifoliata foram plantadas em Comendador Gomes. Em dezembro de 2006, plantas com interenxerto de trifoliata ou de tangerina Cleópatra mostravam sintomas da MSC na copa e o sintoma-diagnóstico no limão-Cravo.

\section{AGRADECIMENTOS}

À Sucocítrico Cutrale e à Fischer Agropecuária pela cessão das áreas e cultivo dos experimentos. Os experimentos foram desenvolvidos com recursos do Projeto MCT/CNPq 50.0043/02-7: Morte Súbita dos Citros: etiologia, epidemiologia e controle.

\section{REFERÊNCIAS}

BASSANEZZI, R.B.; BERGAMIN FILHO, A.; AMORIM, L.; GIMENES-FERNANDES, N.; GOTTWALD, T.R.; BOVÉ, J.M. Spatial and temporal analyses of Citrus Sudden Death as a tool to generate hypotheses concerning its etiology. Phytopatology, St Paul, n.93, p. 502-512, 2003.

BOVÉ, J.M.; GARNIER, M.; GIMENES-FERNANDES, N.; BASSANEZZI, R.B.; YAMAMOTO, P.T.; AYRES, A.J. Sudden death disease of sweet orange trees on Rangpur lime: a hypothesis. Araraquara: Fundecitrus, 2002. 5p. Relatório.
GIMENES-FERNANDES, N.; BASSANEZZI, R.B. Doença de causa desconhecida afeta pomares cítricos no norte de São Paulo e sul do Triângulo Mineiro. Summa Phytopatologica, Botucatu, n.27, p.93, 2001.

GIMENES-FERNANDES, N.; BASSANEZI, R. B. Morte súbita. In: Manejo Integrado de doenças de citros. Fitopatologia Brasileira, Brasília, v.28, p.66-72, 2003. Suplemento.

MACCHERONI, W.; ALEGRIA, M.C.; GREGGIO, C.C.; PIAZZA, J.P.; KAMLA, R.F.; ZACHARIAS, P.R.; BAR-JOSEPH, M.; KITAJIMA, E.W.; ASSUMPÇÃO, L.C.; CAMAROTTE, G.; CARDOZO, J.; CASAGRANDE, E.C.; FERRARI, F.; FRANCO, S.F.; GIACHETTO, P.F.; GIRASOL, A.; JORDAO, H.; SILVA, V.H.; SOUZA, L.C.; AGUILAR-VILDOSO, C.I.; ZANCA, A.S.; ARRUDA, P.; KITAJIMA, J.P.; REINACH, F.C.; FERRO, J.A.; DA SILVA, A.C. Identification and genomic characterization of a new virus (Tymoviridae family) associated with citrus sudden death disease. Journal of Virology, Washington, v.79, n.5, p.30283037,2005 .

MULLER, G.W.; NEGRI, J.D.; AGUILAR-VILDOSO, C.I.; MATTOS JUNIOR, D.; POMPEU JUNIOR, J.; TEOFILO SOBRINHO, J.; CARVALHO, S.A.; GIROTTO, L.F.; MACHADO, M.A. Morte Súbita dos Citros: uma nova doença na citricultura brasileira. Laranja, Cordeirópolis, v.23. n.2, p.371-386, 2002.

YAMAMOTO, P.T.; JESUS JUNIOR, W.C.; BASSANEZZI, R.B.; SANCHES, A.L.; AYRES, A.J.; GIMENES-FERNANDES, N.; BOVÉ, J.M. Transmission of the agent inducing symptoms of citrus sudden death by graft-inoculation under insect-proof conditions. Fitopatologia Brasileira, Brasília, v.28, p. 265, 2003. Suplemento. 